\title{
Systematic Reviews of Topical Fluorides for Dental Caries: A Review of Reporting Practice
}

\author{
S. ljaz R.E. Croucher V.C.C. Marinho \\ Clinical and Diagnostic Oral Sciences, Institute of Dentistry, Barts and The London School of Medicine and \\ Dentistry, Queen Mary, University of London, London, UK
}

\section{Key Words}

Dental caries - Meta-analysis · Systematic review •

Topical fluoride

\begin{abstract}
This paper aims to assess systematic reviews on the cariespreventive effect of topical fluorides, identifying key content and reporting quality issues to be considered by researchers planning a review in this area. Published systematic reviews and meta-analyses of any topical fluoride intervention for caries control were included. Relevant databases were searched (December 2009), along with reference lists of included publications. Thirty-eight reports were identified and assessed. A majority of these focused on the child/adolescent population, fluoride toothpastes, no treatment/placebo comparisons, and had caries increment as the main outcome. Complete reporting of eligibility criteria (PICOS) was uncommon, except in Cochrane reviews. Less than half reported searching multiple sources and only one third reported a search strategy. Duplicate study selection and data extraction was reported in $27(71 \%)$ and $16(42 \%)$ reviews, respectively; quality assessment of included studies was not reported in one third of the reviews. Meta-analysis was reported in $20(52 \%)$ reviews, with six not reporting the methods of synthesis used, 17 formally assessing heterogeneity, and 12 reporting analyses for its exploration. This study
\end{abstract}

shows that some content features have been covered more often than others in existing fluoride reviews, while some relevant features are yet to be addressed. Also, reporting of several methodological aspects are below an acceptable level, except for Cochrane reviews. Current reporting guidelines for systematic reviews of interventions (e.g. PRISMA) and sources of high-quality existing reviews (e.g. The Cochrane Library) should be closely followed to enhance the validity and relevance of future topical fluoride reviews.

Copyright $\odot 2010$ S. Karger AG, Basel

Systematic reviews provide the foundation for better practice and new research in all areas of healthcare and have already answered important questions regarding the effects of fluoride on caries prevention. Consequently, they are becoming more influential as a foundation for preventive practice and policy in dentistry. A systematic review attempts to collate all empirical evidence that fits pre-specified eligibility criteria in order to answer a specific research question; it uses explicit, systematic methods that minimize bias, thus providing reliable findings from which conclusions can be drawn [Antman et al., 1992; Oxman and Guyatt, 1993]. It may or may not include a meta-analysis, which is a statistical pooling of results from two or more independent studies. Systematic reviews are still a relatively new kind of research in den-

\section{KARGER}

Fax +4161306 1234 E-Mail karger@karger.ch www.karger.com
(C) 2010 S. Karger AG, Basel 0008-6568/10/0446-0579\$26.00/0

Accessible online at: www.karger.com/cre
Sharea Ijaz

Clinical and Diagnostic Oral Sciences

Barts and the London Institute of Dentistry

4 Newark Street, London E1 2AT (UK)

Tel. +44 207882 8625, Fax +44 207377 7064, E-Mail shareaijaz@yahoo.com 
tistry though [Marinho, 2003], and there is still room for improvement in the quantity, in terms of subject areas covered, and quality of both the conduct and the reporting of systematic reviews in the field [Glenny et al., 2003; Bader and Ismail, 2004; Richards, 2004; Major et al., 2006].

The various topical fluoride interventions have over six decades of experimental research supporting their value as anticaries measures, and these were the focus of some of the first meta-analyses in dentistry [Stamm et al., 1984; Clark et al., 1985]. Existing systematic reviews of topical fluoride interventions may reflect the available primary research in the field, and their reporting quality may vary. Nevertheless, the breadth of topical fluoride interventions, comparisons, populations, and outcomes covered by published systematic reviews and meta-analyses, and the methodological quality of these reviews, have not been reported previously. Highlighting which direction future reviews in this area should take based on past practice to avoid duplication of effort while advancing knowledge reliably is important, and this should be done in the light of ongoing methodological advancements so as to enhance their validity and applicability.

In 1996, an international group developed a reporting guideline, the QUOROM Statement (QUality Of Reporting Of Meta-analyses), to improve the reporting of systematic reviews and meta-analyses in healthcare research [Moher et al., 1999]. The recent publication of 'Preferred reporting items for systematic reviews and meta-analyses', the PRISMA statement, is an improvement on that guideline [Liberati et al., 2009; Moher et al., 2009]. In addition to the QUOROM items, PRISMA now asks the review authors to make a protocol for the review accessible; to report at least one complete electronic search; to assess risk of bias in and across included studies (along with the selective reporting of outcomes); to report limitations of the review, future research implications and sources of funding. The PRISMA statement has made it clear that the quality and content of systematic reviews is constantly being improved, and has also identified The Cochrane Collaboration as the leader in the field since all these new items are already an essential part of Cochrane reviews. Thus, new reviews incorporating these advancements should have enhanced quality and generate more reliable estimates of treatment effects.

The aim of this paper is to describe the most important features of systematic reviews and meta-analyses on topical fluorides for caries prevention and treatment in terms of content and reporting quality by collating those published up to and including 2009. A comprehensive search and an appraisal in the light of current reporting guidelines (PRISMA) has enabled us to identify important issues that need consideration by researchers planning a systematic review in this area of dentistry.

\section{Materials and Methods}

An electronic search without date or language restrictions was undertaken in December 2009 of: MEDLINE (via OVID including old MEDLINE), The Cochrane Database of Systematic Reviews (CDSR) and The Centre for Reviews and Dissemination (CRD) databases [including DARE (Database of Abstracts of Reviews of Effects), NHSEED (National Health Service Economic Evaluation Database), and HTA (Health Technology Assessment)]. The search terms 'caries AND fluoride' were used in all the searches performed, but a more detailed search strategy was used in MEDLINE (online supplementary material, www. karger.com/doi/10.1159/000322132). This was supplemented by searching the reference lists of the included reviews.

Only completed published intervention systematic reviews and meta-analyses, including any types of study design, assessing the anticaries effects of any topical fluoride therapy (TFT), including toothpaste, mouthrinse, gel, varnish, paint-on solution, whether used alone, or in combination with another TFT, or as part of a larger group of anticaries interventions in any population group were considered relevant for inclusion. Any review that incorporated at least two of the key characteristics of a systematic review outlined in section 1.2.2 of The Cochrane Handbook of Systematic Reviews of Interventions [Higgins and Green, 2008] was considered.

For each of the identified reviews included in this study, the following data were then extracted on a standard form: year of publication; whether a clear objective and eligibility criteria (in terms of participants, interventions, comparisons and outcomes - PICOS) were stated in the review; types of intervention(s), comparison(s) and population group(s) addressed; main outcomes addressed; number and types of studies included; methods used for study identification, study selection, quality assessment (risk of bias) and data extraction of included studies; effect measures used; whether a quantitative synthesis was done; statistical methods used in the synthesis (fixed effect or random effects); assessment, exploration and factors explored for heterogeneity; assessment and exploration of publication or reporting bias; whether cost/economic evaluation was reported and in what format. These data were then summarized so as to identify the most important issues in the conduct and reporting of topical fluoride reviews. Search strategy development, study selection and data collection were done by one author (S.I.) in consultation with the other (V.C.C.M.).

\section{Results}

The searches resulted in 150 citations from MEDLINE, 17 from CDSR, 39 from DARE, 17 from NHSEED, and 7 from HTA databases. These results (230 titles and 
abstracts) were read for identifying relevant systematic reviews and meta-analyses of topical fluoride interventions for caries. Reasons for exclusions at this stage were: duplicate citations $(n=64)$, traditional narrative reviews $(\mathrm{n}=46)$, reviews of non-TFT interventions $(\mathrm{n}=42)$; technology or economic assessments that were not systematic reviews $(\mathrm{n}=23)$.

The remaining 55 papers were then read in full text. Of these, five were protocols of ongoing systematic reviews, six were response publications to already published meta-analyses, three were method papers, and three were commentaries on a TFT systematic review. One did not report the review methodology in sufficient detail while one focused purely on assessment of epidemiological data and did not assess effectiveness of the TFT intervention. These 19 papers were excluded.

Thirty-six papers were included. Two other reviews were identified from the reference lists of the included reviews. Thus a total of 38 systematic reviews addressing effectiveness of some form of TFT for caries were identified. Tables 1 and 2 summarise the data extracted from these reports (general content and methodological features, and features specifically related to data synthesis, respectively). The oldest included review was a metaanalysis from 1984 and the latest from 2009. The greatest number of reviews was published between 2000 and 2004 (fig. 1).

\section{Reporting of Objectives and Eligibility Criteria}

Although all publications stated objectives at least in terms of 'intervention for condition', most of these did not provide complete information on eligibility criteria in PICOS format (population, intervention, comparison, outcome, study design), except in Cochrane reviews.

\section{Characteristics of Studies Included - PICOS}

Populations. The most covered group was children and/or adolescents from the general population $(\mathrm{n}=21$, 55\%). Three reviews addressed fixed orthodontic appliance wearing patients, two addressed adults, and two covered high caries risk individuals only. Eight did not specify the population group addressed.

Interventions. The topical fluoride intervention most commonly addressed was toothpaste $(\mathrm{n}=10,26 \%)$. Varnish was the main intervention of interest in nine reviews, mouthrinses in four, and gels in three. Nine reviews addressed any TFT, while two addressed combinations of TFT. One review specifically addressed silver diamine fluoride - a type of paint-on solution.
Comparisons. The comparison most commonly addressed was intervention (TFT) versus placebo or no treatment ( $\mathrm{n}=16,42 \%)$. This was followed by comparisons of one concentration of fluoride toothpaste versus another $(n=5)$, and comparisons of one specific fluoride agent/compound in toothpaste versus another $(\mathrm{n}=3)$. Two reviews addressed comparisons of one type of TFT against another, while 13 (34\%) did not specify the comparisons addressed.

Outcomes. Caries increment was the most common outcome measure $(\mathrm{n}=31,81 \%)$, followed by caries incidence $(n=4)$, caries arrest $(n=3)$ and caries progression $(n=2)$. Adverse effects and patient-reported outcomes were not measured as a primary/main outcome in any review (although adverse events were mentioned as secondary outcomes in 11 reviews).

Study Design. The most common type of study considered was controlled clinical trial $(n=34,90 \%)$. Four reviews considered various non-RCT designs (prospective controlled studies, uncontrolled longitudinal studies, and even reviews and guidelines) for inclusion and two reviews considered economic evaluations.

\section{Search Methods Used}

Six reviews (16\%) did not report any search methods (sources, dates, languages, search terms, etc.) for studies, although five of these were published before the first reporting guideline came out in 1999 with clear recommendations on this aspect [Moher et al., 1999]. Only 12 (31\%) of the 38 reviews reported a complete search strategy for at least one database - mostly Cochrane reviews, while 17 reported search terms, key words or concepts used for searching.

Seventeen reviews (45\%) reported searching multiple databases (more than two) electronically while six reported searching MEDLINE and The Cochrane Library databases, apparently treating The Cochrane Library as one database. Nineteen (50\%) reported complementing electronic search with searching one or more other sources (reference/hand/grey literature/authors).

\section{Study Selection and Data Extraction}

Three reviews (8\%) did not report on the study selection process. Study selection was reported to be performed in duplicate in 27 (71\%) reviews. Of these, 20 reviews reported duplicate study selection in the entire sample while seven reported the same in a random one third of the sample. For eight reviews it could not be judged if it was done in duplicate. 


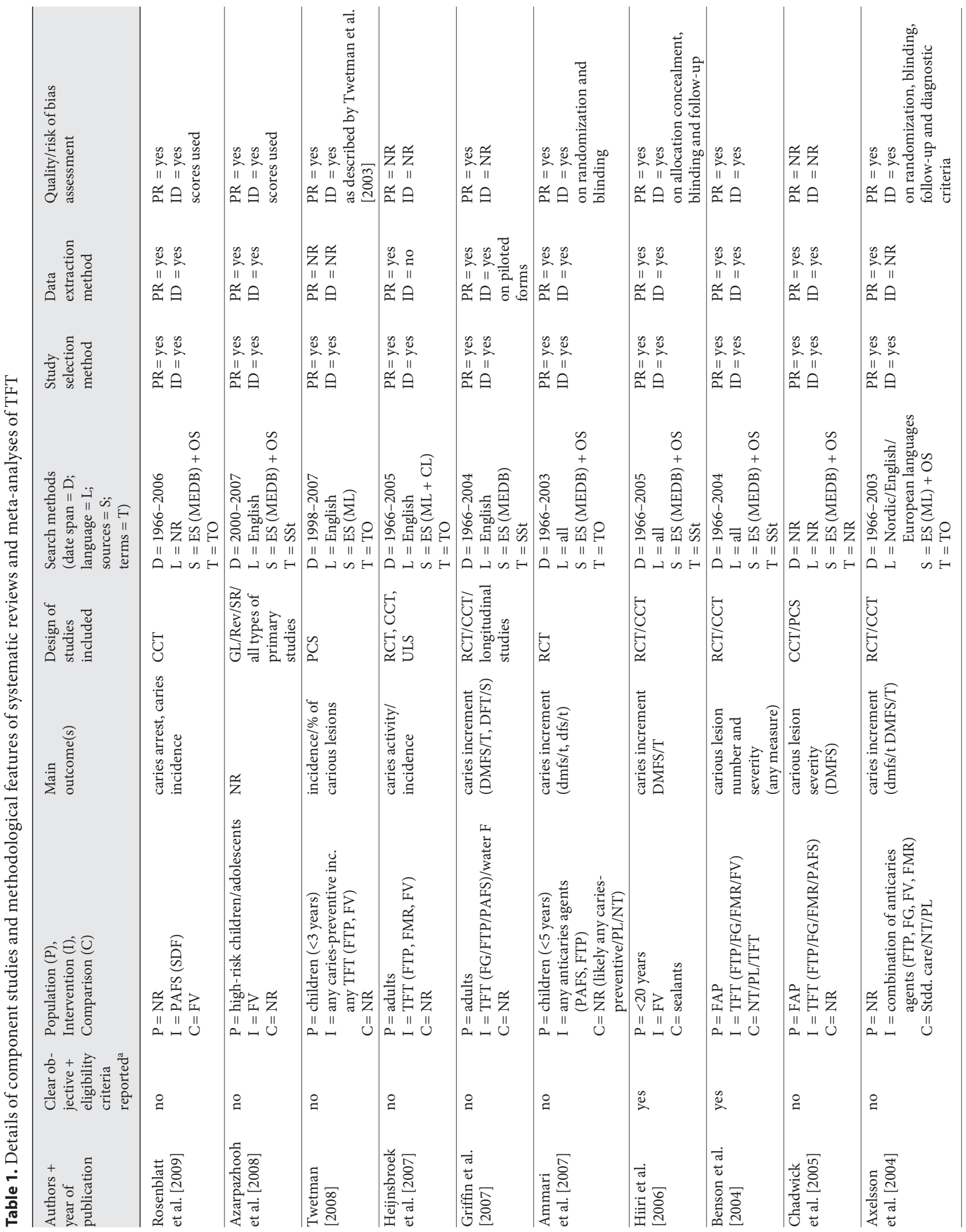




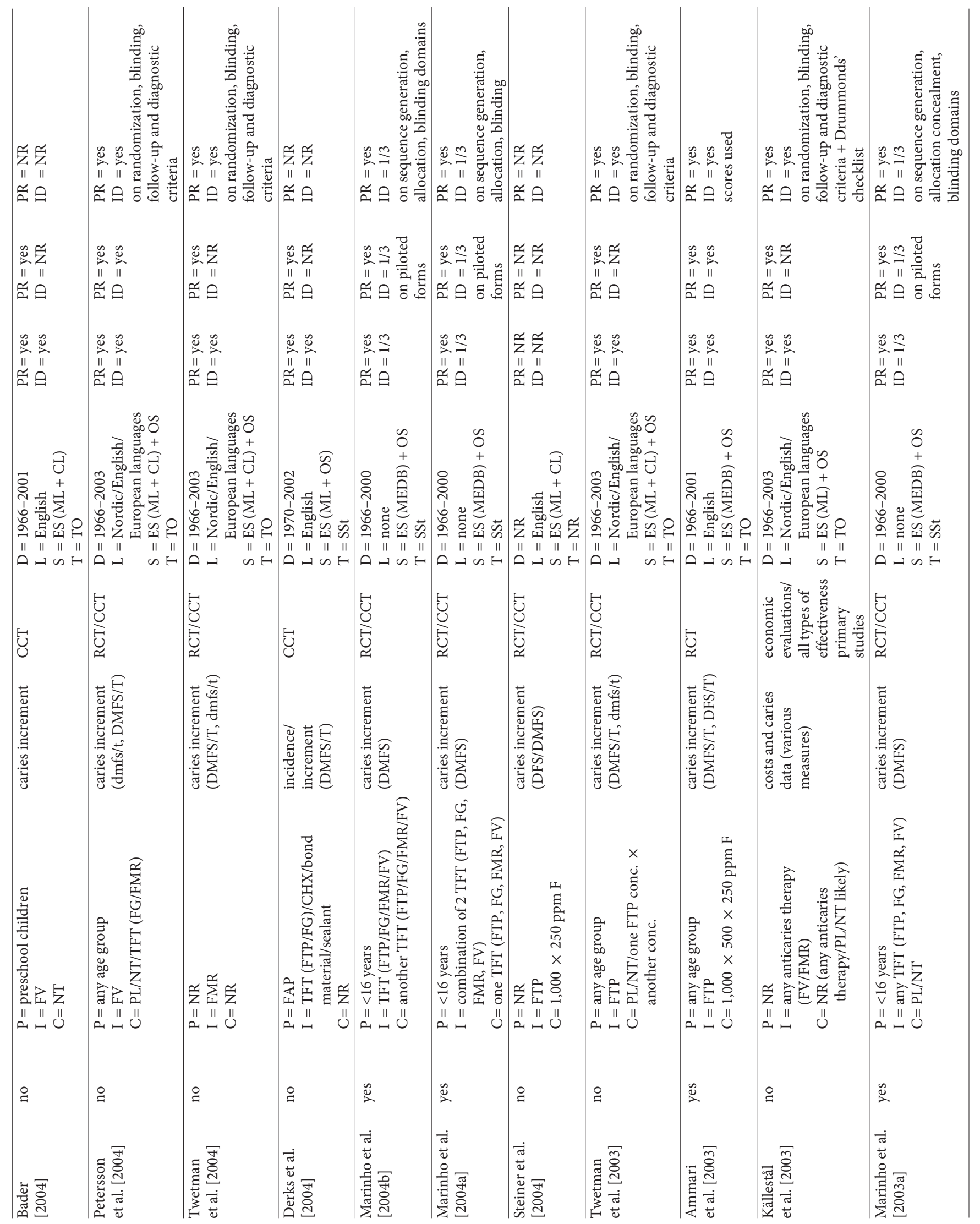




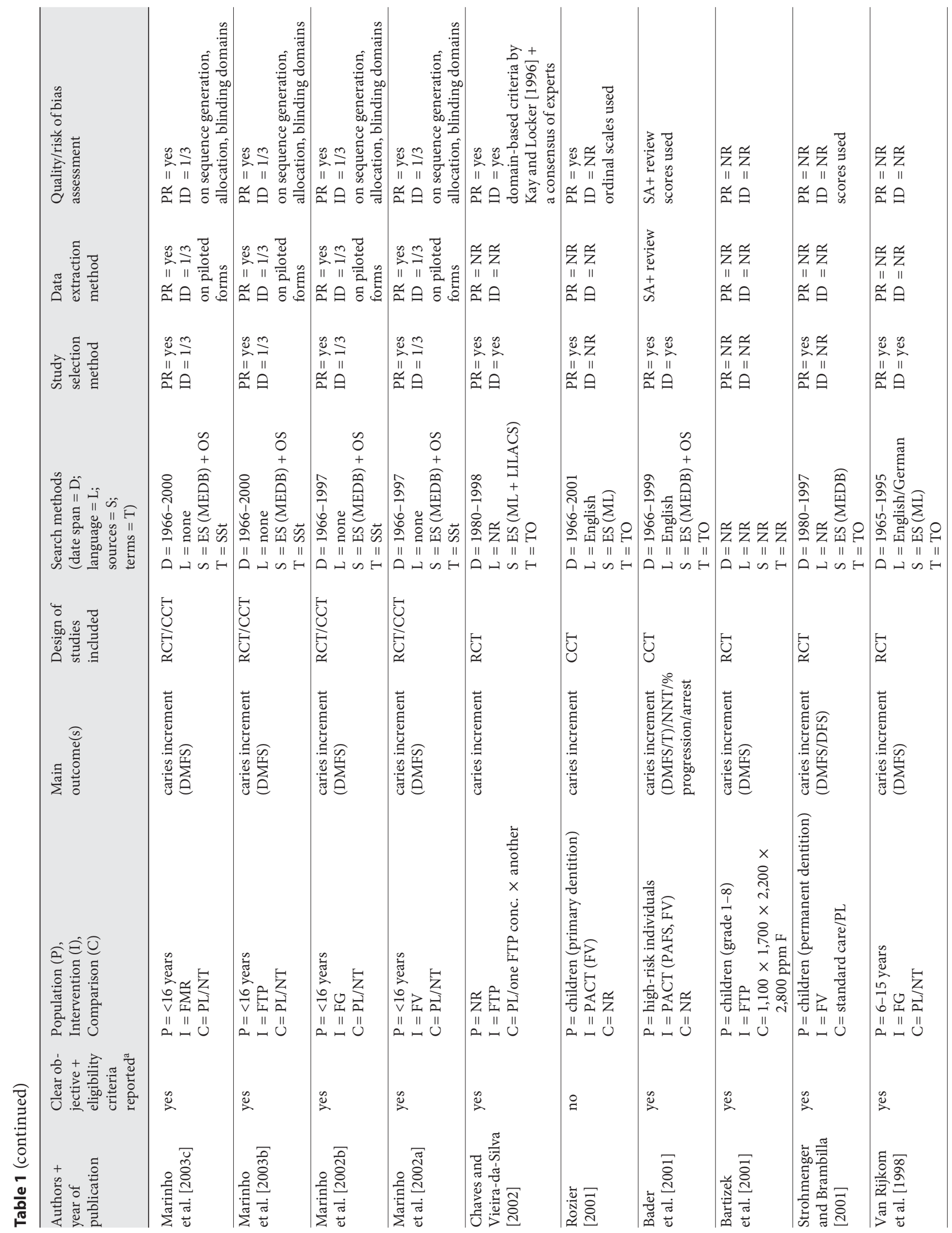




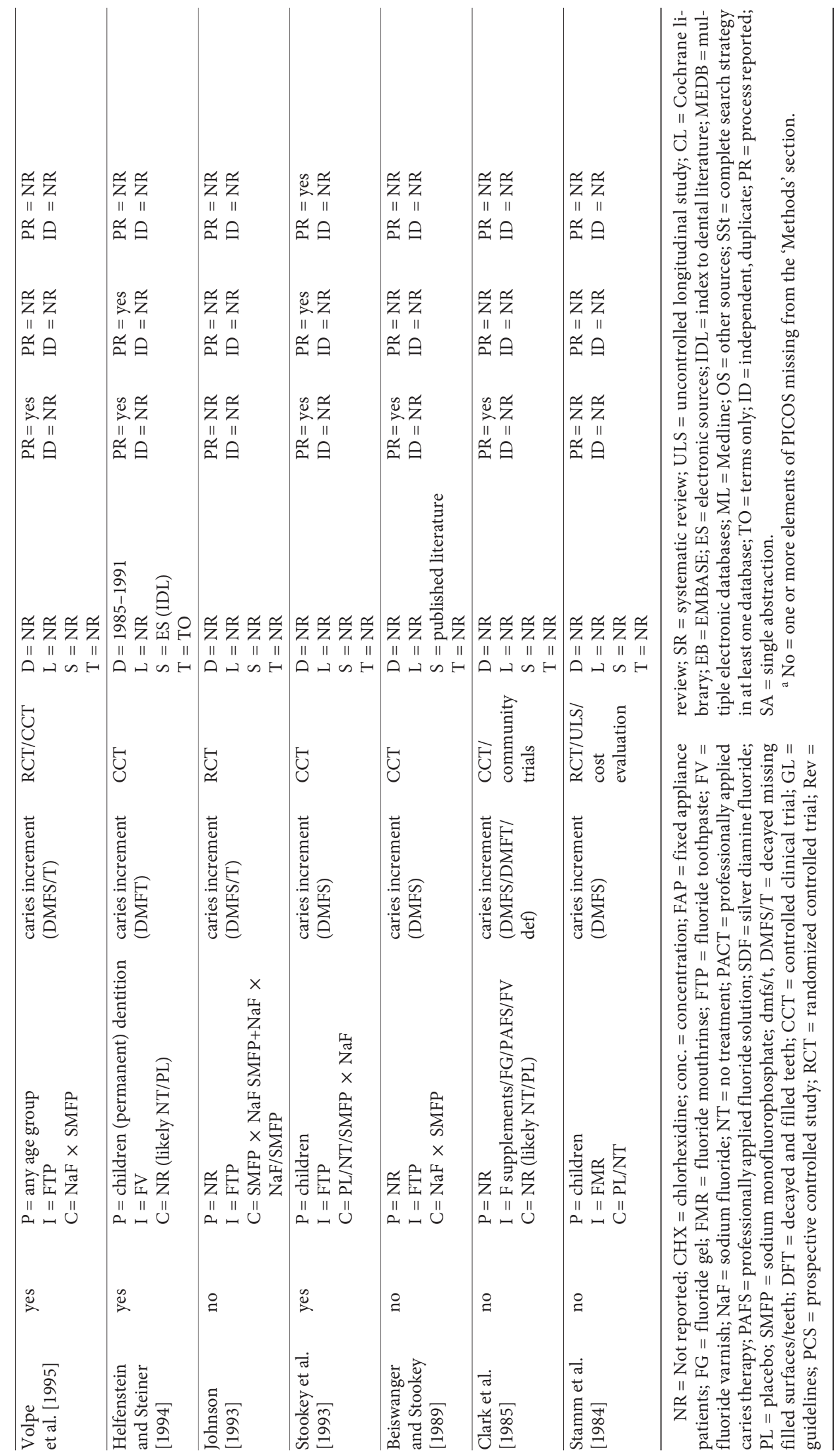


Table 2. Summary of data synthesis features in systematic reviews and meta-analyses of TFT

\begin{tabular}{|c|c|c|c|c|c|c|}
\hline $\begin{array}{l}\text { Authors }+ \\
\text { year of } \\
\text { publication }\end{array}$ & $\begin{array}{l}\text { Studies } \\
\text { included }\end{array}$ & $\begin{array}{l}\text { Primary } \\
\text { effect } \\
\text { measures }\end{array}$ & $\begin{array}{l}\text { Method of } \\
\text { quantitative } \\
\text { synthesis }\end{array}$ & Assessment/exploration of heterogeneity & $\begin{array}{l}\text { Assess./explo- } \\
\text { ration of pub- } \\
\text { lication bias }\end{array}$ & $\begin{array}{l}\text { Economic } \\
\text { evaluation }\end{array}$ \\
\hline $\begin{array}{l}\text { Rosenblatt } \\
\text { et al. [2009] }\end{array}$ & 2 & PF, NNT & NR & NR & NR & NR \\
\hline $\begin{array}{l}\text { Azarpazhooh } \\
\text { et al. [2008] }\end{array}$ & 7 & NR & NR & NR & NR & NR \\
\hline $\begin{array}{l}\text { Twetman } \\
{[2008]}\end{array}$ & 22 & NR & NR & NR & NR & NR \\
\hline $\begin{array}{l}\text { Heijnsbroek } \\
\text { et al. [2007] }\end{array}$ & 6 & NR & NR & NR & NR & NR \\
\hline $\begin{array}{l}\text { Griffin } \\
\text { et al. [2007] }\end{array}$ & 20 & $\mathrm{RR}, \mathrm{MD}$ & RE MA & $\chi^{2}, \mathrm{I}^{2} /$ sensitivity analysis for study design & NR & NR \\
\hline $\begin{array}{l}\text { Ammari } \\
\text { et al. [2007] }\end{array}$ & 7 & $\mathrm{PF}$ & NR & NR & NR & NR \\
\hline $\begin{array}{l}\text { Hiiri } \\
\text { et al. [2006] }\end{array}$ & 4 & RR & NR & NR & NR & NR \\
\hline $\begin{array}{l}\text { Benson } \\
\text { et al. [2004] }\end{array}$ & 15 & $\begin{array}{l}\text { WMD, } \\
\text { Peto's OR }\end{array}$ & NR & NR & NR & NR \\
\hline $\begin{array}{l}\text { Chadwick } \\
\text { et al. [2005] }\end{array}$ & 6 & $\mathrm{PF}$ & NR & NR & NR & NR \\
\hline $\begin{array}{l}\text { Axelsson } \\
\text { et al. [2004] }\end{array}$ & 24 & NR & NR & NR & NR & NR \\
\hline $\begin{array}{l}\text { Bader } \\
\text { et al. [2004] }\end{array}$ & $6(\mathrm{FV})$ & $\begin{array}{l}\% \text { caries } \\
\text { reduction }\end{array}$ & NR & NR & NR & NR \\
\hline $\begin{array}{l}\text { Petersson } \\
\text { et al. [2004] }\end{array}$ & 24 & $\mathrm{PF}$ & $\begin{array}{l}\text { NR } \\
\text { (likely done) }\end{array}$ & NR & NR & NR \\
\hline $\begin{array}{l}\text { Twetman } \\
\text { et al. [2004] }\end{array}$ & 25 & $\mathrm{PF}$ & $\begin{array}{l}\text { NR } \\
\text { (likely done) }\end{array}$ & $\begin{array}{l}\mathrm{NR} / \text { correlation analysis on intervention and population } \\
\text { features }\end{array}$ & NR & NR \\
\hline $\begin{array}{l}\text { Derks } \\
\text { et al. [2004] }\end{array}$ & 15 & $\mathrm{PF}$ & $\mathrm{NR}$ & $\mathrm{NR}$ & NR & NR \\
\hline $\begin{array}{l}\text { Marinho } \\
\text { et al. [2004b] }\end{array}$ & $\begin{array}{l}17(15 \\
\text { for MA) }\end{array}$ & $\mathrm{PF}$ & RE MA & $\begin{array}{l}\chi^{2}+I^{2} \text { tests/RE MR sensitivity subgroup analyses on pre- } \\
\text { defined and not pre-defined aspects of study quality, and } \\
\text { participants, intervention, and outcome-related features }\end{array}$ & $\begin{array}{l}\text { funnel plot/ } \\
\text { formal tests }\end{array}$ & NR \\
\hline $\begin{array}{l}\text { Marinho } \\
\text { et al. [2004a] }\end{array}$ & $\begin{array}{l}12(9 \\
\text { for MA) }\end{array}$ & $\mathrm{PF}$ & RE MA & $\begin{array}{l}\chi^{2}+\mathrm{I}^{2} \text { tests/RE MR sensitivity subgroup analyses on pre- } \\
\text { defined and not pre-defined aspects of study quality, and } \\
\text { participants, intervention, and outcome-related features }\end{array}$ & $\begin{array}{l}\text { funnel plot/ } \\
\text { formal tests }\end{array}$ & NR \\
\hline $\begin{array}{l}\text { Steiner } \\
\text { et al. [2004] }\end{array}$ & 4 & $\mathrm{PF}$ & $\mathrm{RE}+\mathrm{FE} \mathrm{MA}$ & Cochran test/NR & NR & NR \\
\hline $\begin{array}{l}\text { Twetman } \\
\text { et al. [2003] }\end{array}$ & 54 & $\mathrm{PF}$ & NR & NR & NR & NR \\
\hline $\begin{array}{l}\text { Ammari } \\
\text { et al. [2003] }\end{array}$ & $\begin{array}{l}7 \text { ( } 5 \text { for } \\
\text { MA) }\end{array}$ & WMD & FE MA & $\mathrm{NR} /$ sensitivity analysis for intervention feature & $\begin{array}{l}\text { funnel plot/ } \\
\text { NR }\end{array}$ & NR \\
\hline $\begin{array}{l}\text { Källestål } \\
\text { et al. [2003] }\end{array}$ & $\begin{array}{l}17(2 \mathrm{FV}, \\
3 \mathrm{FMR})\end{array}$ & NR & NR & NR & $\mathrm{NR}$ & $\begin{array}{l}\text { identified + } \\
\text { quality- } \\
\text { assessed } \\
\text { economic } \\
\text { evaluations }\end{array}$ \\
\hline $\begin{array}{l}\text { Marinho } \\
\text { [2003a] }\end{array}$ & $\begin{array}{l}144(133 \\
\text { for MA) }\end{array}$ & $\mathrm{PF}$ & RE MA & $\begin{array}{l}\chi^{2}+\mathrm{I}^{2} \text { tests/RE MR, sensitivity subgroup analyses on pre- } \\
\text { defined and not pre-defined aspects of study quality, and } \\
\text { participants, intervention, and outcome-related features }\end{array}$ & $\begin{array}{l}\text { funnel plot/ } \\
\text { formal tests }\end{array}$ & NR \\
\hline $\begin{array}{l}\text { Marinho } \\
{[2003 c]}\end{array}$ & $\begin{array}{l}36(34 \\
\text { for MA) }\end{array}$ & $\mathrm{PF}$ & RE MA & $\begin{array}{l}\chi^{2}+\mathrm{I}^{2} \text { tests/RE MR, sensitivity analyses on pre-defined and } \\
\text { not pre-defined aspects of study quality, and participants, } \\
\text { intervention, and outcome-related features }\end{array}$ & $\begin{array}{l}\text { funnel plot/ } \\
\text { formal tests }\end{array}$ & NR \\
\hline $\begin{array}{l}\text { Marinho } \\
{[2003 \mathrm{~b}]}\end{array}$ & $\begin{array}{l}74(70 \\
\text { for MA) }\end{array}$ & $\mathrm{PF}$ & RE MA & $\begin{array}{l}\chi^{2}+\mathrm{I}^{2} \text { tests/RE MR, sensitivity analyses on pre-defined and } \\
\text { not pre-defined aspects of study quality, and participants, } \\
\text { intervention, and outcome-related features }\end{array}$ & $\begin{array}{l}\text { funnel plot/ } \\
\text { formal tests }\end{array}$ & NR \\
\hline
\end{tabular}


Table 2 (continued)

\begin{tabular}{|c|c|c|c|c|c|c|}
\hline $\begin{array}{l}\text { Authors + } \\
\text { year of } \\
\text { publication }\end{array}$ & $\begin{array}{l}\text { Studies } \\
\text { included }\end{array}$ & $\begin{array}{l}\text { Primary } \\
\text { effect } \\
\text { measures }\end{array}$ & $\begin{array}{l}\text { Method of } \\
\text { quantitative } \\
\text { synthesis }\end{array}$ & Assessment/exploration of heterogeneity & $\begin{array}{l}\text { Assess./explo- } \\
\text { ration of pub- } \\
\text { lication bias }\end{array}$ & $\begin{array}{l}\text { Economic } \\
\text { evaluation }\end{array}$ \\
\hline $\begin{array}{l}\text { Marinho } \\
\text { et al. [2002b] }\end{array}$ & $\begin{array}{l}25(23 \\
\text { for MA) }\end{array}$ & PF, SMD & RE MA & $\begin{array}{l}\chi^{2}+\mathrm{I}^{2} \text { tests/RE MR, sensitivity subgroup analyses on pre- } \\
\text { defined and not pre-defined aspects of study quality, and } \\
\text { participants, intervention, and outcome-related features }\end{array}$ & $\begin{array}{l}\text { funnel plot/ } \\
\text { formal tests }\end{array}$ & NR \\
\hline $\begin{array}{l}\text { Marinho } \\
\text { et al. [2002a] }\end{array}$ & $\begin{array}{l}9(7 \text { for } \\
\text { MA) }\end{array}$ & PF, SMD & RE MA & $\begin{array}{l}\chi^{2}+\mathrm{I}^{2} \text { tests/RE MR, sensitivity analyses on pre-defined and } \\
\text { not pre-defined aspects of study quality, and participants, } \\
\text { intervention, and outcome-related features }\end{array}$ & $\begin{array}{l}\text { funnel plot/ } \\
\text { formal tests }\end{array}$ & NR \\
\hline $\begin{array}{l}\text { Chaves and } \\
\text { Vieira-da-Silva } \\
\text { [2002] }\end{array}$ & 22 & $\%$ difference & FE MA & Q test/NR & NR & NR \\
\hline $\begin{array}{l}\text { Rozier } \\
{[2001]}\end{array}$ & $7(\mathrm{FV})$ & PF, NNT & NR & NR & NR & NR \\
\hline $\begin{array}{l}\text { Bader } \\
\text { et al. [2001] }\end{array}$ & 27 & NR & NR & NR & NR & NR \\
\hline $\begin{array}{l}\text { Bartizek } \\
\text { et al. [2001] }\end{array}$ & 6 & SMD & MA (type NR) & $\chi^{2} / \mathrm{NR}$ & NR & NR \\
\hline $\begin{array}{l}\text { Strohmenger } \\
\text { and Brambilla } \\
\text { [2001] }\end{array}$ & 3 & WMD & RE MA & Q test/NR & NR & NR \\
\hline $\begin{array}{l}\text { Van Rijkom } \\
\text { et al. [1998] }\end{array}$ & 17 & PF & MA (type NR) & NR/MR analysis on population and intervention features & $\begin{array}{l}\text { funnel plot/ } \\
\text { NR }\end{array}$ & $\begin{array}{l}\text { reported cost } \\
\text { info + NNT }\end{array}$ \\
\hline $\begin{array}{l}\text { Volpe } \\
\text { et al. [1995] }\end{array}$ & 4 & WMD & MA (type NR) & NR/subgroup analysis for study design features & NR & NR \\
\hline $\begin{array}{l}\text { Helfenstein } \\
\text { and Steiner } \\
\text { [1994] }\end{array}$ & 8 & PF & RE MA & $\begin{array}{l}\chi^{2} / \text { correlation analysis on aspects of study quality, and } \\
\text { participants, intervention, and outcome-related features }\end{array}$ & NR & NR \\
\hline $\begin{array}{l}\text { Johnson } \\
\text { [1993] }\end{array}$ & $\begin{array}{l}10 \text { ( } 9 \text { for } \\
\text { MA) }\end{array}$ & WMD & MA (type NR) & $\chi^{2} /$ subgroup analysis for study design features & NR & NR \\
\hline $\begin{array}{l}\text { Stookey } \\
\text { et al. [1993] }\end{array}$ & 13 & WMD & MA (type NR) & $\chi^{2} /$ subgroup analysis for study design features & NR & NR \\
\hline $\begin{array}{l}\text { Beiswanger } \\
\text { and Stookey } \\
{[1989]}\end{array}$ & 20 & $\%$ difference & $\begin{array}{l}\text { NR } \\
\text { (likely done) }\end{array}$ & NR & NR & NR \\
\hline $\begin{array}{l}\text { Clark } \\
\text { et al. [1985] }\end{array}$ & NR & WMD & RE MA & NR & NR & NR \\
\hline $\begin{array}{l}\text { Stamm } \\
\text { et al. [1984] }\end{array}$ & NR & WMD & MA (type NR) & NR & NR & CEA. \\
\hline
\end{tabular}

$\mathrm{NR}=$ Not reported; $\mathrm{OR}$ = odds ratio; $\mathrm{MD}$ = mean difference; $\mathrm{PF}$ = prevented fraction; $\mathrm{RR}$ = risk ratio; $\mathrm{SMD}=$ standardized mean difference; $\mathrm{WMD}$ = weighted mean difference; $\mathrm{FE}$ = fixed effect; $\mathrm{MA}$ = meta-analysis; $\mathrm{MR}$ = meta-regression; $\mathrm{RE}=$ random effect; CEA = cost-effective analysis; $\mathrm{USD}=$ US dollar.

For eleven reviews (29\%) the data extraction method was not reported and for ten we could not judge whether data extraction was done in duplicate. Duplicate data extraction was clearly reported in $16(42 \%)$ reviews; nine reviews reporting duplicate independent data extraction for the entire sample and seven reporting the same in a random one third of the total sample of studies. One review reported single abstraction of data. Only Cochrane reviews and those from The Swedish Council of Technol- ogy Assessment in Health Care reported using piloted forms for data extraction.

\section{Methodological Quality Assessment}

Thirteen reviews (34\%) did not report assessing the quality of included studies. However, an equal number of reviews reported independent duplicate assessment of study quality in the entire sample. Another seven reviews (the series of Cochrane reviews 2002-2004) reported do- 


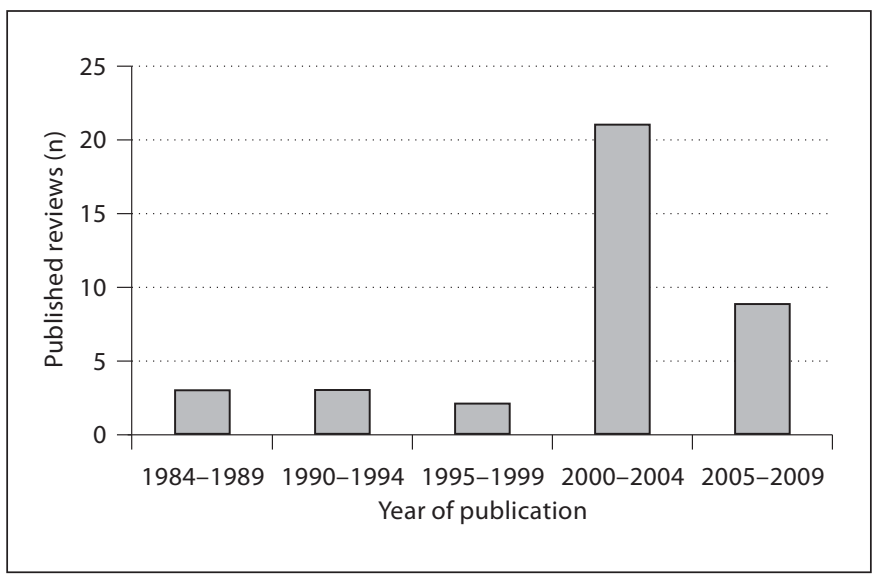

Fig. 1. Frequency of systematic reviews and meta-analyses on topical fluoride by year of publication.

main-based assessment of risk of bias in duplicate in a random one third of included studies. Of the rest, one used single assessment and four did not give enough detail to allow judgement of duplicate assessment.

A total of $16(42 \%)$ reviews (including the Cochrane reviews and Swedish Council of Technology Assessment in Health Care series of reviews) reported quality assessment in the domains of allocation concealment and blinding. Four reviews reported using scores for quality assessment - all published after 2000. An assessment of risk of selective outcome reporting bias within studies was not specified by any of the included reviews, reflecting its very recent addition to the risk of bias aspect.

\section{Quantitative Synthesis}

Summary effect measures could not be identified for 6 reviews. Prevented fraction was the most common effect measure used $(\mathrm{n}=18,47 \%)$ followed by weighted mean difference $(n=7)$. Other effect measures used included risk ratio, standardized mean difference, and numbers needed to treat.

Of the 20 (53\%) reporting a meta-analysis, 11 reported a random effects meta-analysis and two reported using fixed effect analysis. One reported using both fixed and random effects models while six did not specify the type of meta-analysis performed.

Assessment of heterogeneity was reported by 17 of those reporting a meta-analysis (85\%); $\chi^{2}$ and $\mathrm{I}^{2}$ statistics were the most commonly used tests $(n=12)$ to assess heterogeneity. Fourteen reviews (70\%) reported additional analyses for exploration of heterogeneity between stud- ies. Cochrane reviews pre-specified the aspects to be assessed in these additional meta-regression, subgroup or sensitivity analyses, and reported any post-hoc decision for further analyses undertaken. These reviews explored heterogeneity through regression analysis on aspects of study quality, baseline caries level, additional fluoride exposure, $\mathrm{F}^{-}$concentration, frequency of TFT use, and mode and form of TFT use. Another eight reviews used sensitivity or subgroup analyses for the aspects of study quality or study design, with five of these published before 2000 .

Nine reviews (24\%) explored publication bias by observing funnel plot asymmetry, and seven of these (all Cochrane reviews) used formal tests for its assessment. One review reported carrying out supplemental analysis including studies published later, one assumed publication bias to be nonexistent, and two just mentioned publication bias in the text.

Only three (8\%) reviews addressed economic data. Of these, one identified economic evaluations on fluoride mouthrinses and varnishes and quality-assessed/graded them, another, assessing fluoride gels, reported numbers needed to treat as a measure of resource intensiveness, and one reported a cost-effectiveness analysis of mouthrinse studies.

\section{Discussion}

This study is the first to provide a comprehensive assessment of the content and reporting quality of systematic reviews and meta-analyses on TFT for dental caries. We included 38 reviews published from 1984 to 2009. This is a relatively large number of systematic reviews/ meta-analyses identified in one particular area of dentistry. This may be partly explained by the fact that two of the first meta-analyses in dentistry appeared exactly on this topic as early as in the mid-1980s [Stamm et al., 1984; Clark et al., 1985], and also by the large amount of experimental evidence published over five decades. In addition, we were deliberately inclusive in classifying a publication as a systematic review in order to get a broader perspective on the development of evidence synthesis in this particular area. The highest number of publications between 2000 and 2004 were associated with the publication of a series of Cochrane reviews and systematic reviews from the Swedish Council of Technology Assessment in Health Care assessing the effectiveness of fluoride toothpastes, mouthrinses, gels and varnishes. 
This study identified some key issues in the published TFT systematic reviews. We found that in terms of content (PICOS), children and adolescents, fluoride toothpastes, no treatment/placebo comparisons, and the outcome of caries increment have been addressed repeatedly. Some important population groups (e.g. adults), TFT interventions (e.g. paint-on solutions), comparisons (e.g. of various application features), and outcomes (e.g. adverse effects, economic) have not been addressed sufficiently though, or have not been covered at all. Some Cochrane reviews that could be identified as protocols at the time of the search, and have now been published, are likely to narrow some of the existing gaps, such as those related to the assessment of direct comparisons of toothpaste application features (fluoride concentration) [Walsh et al., 2010] and of adverse effects (fluorosis) [Wong et al., 2010].

We had expected that the dissemination of methods for conducting systematic reviews from the mid 1990s [CRD, 1996; Clarke and Oxman, 2002], and the publication of reporting guidelines for systematic reviews since 1999 [Moher et al., 1999] would result in an overall improved reporting quality in the TFT systematic reviews that followed. Higher quality reviews that were published post QUOROM have been reported in other healthcare areas [Delaney et al., 2005; Al Faleh and Al-Omran, 2009]. This appears to be the case for TFT systematic reviews as well, where the reviews published after QUO$\mathrm{ROM}$ were of better overall reporting quality than those published before it. There remains room for improvement though. Even very recently published reviews did not adopt the clear structured format (PICOS) advised by the guidelines. Reporting of search methods was also found to be largely inadequate, particularly the complete reporting of a search strategy which was rare outside of Cochrane reviews. In addition, searching multiple sources for studies was reported by only half of the reviews even if pre-QUOROM publications are disregarded.

Published reviews sometimes reported searching the Cochrane Library without specifying the databases searched within it. The Cochrane Library includes specific databases for searching various types of studies such as Cochrane and non-Cochrane systematic reviews, controlled trials, methods studies, economic evaluations, and health technology assessments. It should be specified which of these were used to locate studies. Nevertheless, methods used for 'selection of studies' were found to be more in line with the current reporting guidelines - done in duplicate - and reported in more detail than they were for data extraction, although both aspects are advised to be equally explicitly reported.

Topical Fluorides Systematic Reviews
Another important finding was that the quality/risk of bias assessment in most reviews did not meet current reporting guidelines, except in Cochrane reviews. For example, the use of summary scores for risk of bias assessment, even though guidelines are explicitly discouraging this approach now [Higgins and Altman, 2008; Liberati et al., 2009]. The assessment of risk of bias in included studies according to the latest PRISMA recommendations is a major development that should be widely adopted.

The use of quantitative synthesis, meta-analysis, was reported in half of the reviews with reporting of the methods of synthesis variable across them. Although heterogeneity was also formally assessed in nearly half of the reviews, its presence was usually not adequately explored by means of subgroup, sensitivity, or meta-regression analyses. The exceptions were, again, Cochrane reviews, which predefined and detailed the analyses and the investigations of potential reasons for heterogeneity between studies to be undertaken, and reported any posthoc decisions on analyses or deviations from protocol with reasons for doing so. In line with a previous study assessing systematic reviews in health care [Moher et al., 2007], assessment of publication bias was also a relatively rare feature in the reviews despite its known importance in affecting reviews' findings. However, a note of caution would be always required in assessing and interpreting heterogeneity and publication bias; there will often be insufficient data for these investigations to be done reliably using statistical methods, and they would be of questionable value when based on very few studies [Higgins et al., 2002; Sterne et al., 2008]. In addition, explorations of heterogeneity that are devised after heterogeneity is identified can at best lead to the generation of hypotheses [Deeks, 2008].

We found that economic evaluations in TFT systematic reviews have been uncommon so far. Current methodological developments from the Cochrane and the Campbell Collaboration (www.campbellcollaboration. org) support the introduction of economic evaluations in systematic reviews, and these have the potential to enhance the applicability of new TFT review's findings, since such evaluations are becoming increasingly important for decision makers to help identify more cost-effective treatments.

Our findings were consistent with those from previous studies of this nature in that the Cochrane reviews performed better than others in reporting quality [Moja et al., 2005; Jørgensen et al., 2006, 2008; Moher et al., 2007; Mrkobrada et al., 2008; Lundh et al., 2009]. Our broad 
inclusion criteria for systematic reviews may be considered a reason for the low review quality observed generally. However, in a recent study of similar nature, restricting inclusion to reviews clearly labelled as systematic reviews did not result in improved overall quality, nor did it explain the differences in quality between Cochrane and non-Cochrane systematic reviews [Lundh et al., 2009].

The suboptimal reporting outside of Cochrane reviews may indicate a low level of awareness regarding existing reporting guidelines for systematic reviews among authors and dental journals, which is understandable considering that these involve relatively new methodology. However, although information on the endorsement by journals of reporting guidelines for systematic reviews (QUOROM/PRISMA) is not available (www.prismastatement.org), the list of around 350 scientific journals officially endorsing the reporting guideline for clinical trials - CONSORT (CONsolidated Standards Of Reporting Trials) included only nine dental journals in early 2010 (www.consort-statement.org). Recent studies suggest that endorsement of reporting guidelines by journals can lead to improved overall quality [Moher et al., 2001, 2007; Plint et al., 2006; Mrkobrada et al., 2008; Alvarez et al., 2009]. With this regard, it has also been suggested that directing continuing education efforts towards journal editors may improve the quality of published research faster than other interventions [Sørensen and Rothman, 2010]. Thus, the endorsement of PRISMA by dental journals may be the simplest way to ensure up-to-the-mark reporting of systematic reviews and meta-analyses in dentistry.

As regards potential limitations of our study, it should be noted that we restricted our search to MEDLINE and certain dedicated databases of systematic reviews. We may have missed out on publications not covered by these and available from other sources. In addition, selection of included studies, and data extraction were done by one author with a second author consulted at each stage and consensus achieved. These were not undertaken independently, which may have allowed some degree of bias. Finally, it should be pointed out that we essentially assessed included reviews for reporting quality with regard to adherence to reporting guidelines. We did not use a review quality assessment tool such as AMSTAR [Shea et al., 2007, 2009] or OQAQ [Oxman and Guyatt, 1991] for their appraisal, although most aspects assessed would also be covered by these tools.

In summary, we have identified some content and reporting quality issues for consideration in future topical fluoride reviews.
In terms of reporting quality, complete reporting of objectives and eligibility criteria (in PICOS format), and of the search strategy, assessment of risk of bias, exploration of heterogeneity, and explicit reporting of the review process - what was and was not done in the review - are important issues in current publications that should be addressed more thoroughly in future reviews. We found the methods and reporting in the Cochrane topical fluoride reviews to be superior to others in general, and in line with PRISMA recommendations. Therefore, future systematic reviews on topical fluorides will benefit from following the PRISMA statement.

In terms of content, these are assessments of interventions and of direct comparisons of application features within interventions, population groups, and outcomes not covered to date or sufficiently. In addition, the relative economic value of topical fluoride therapies should also be assessed more widely. The CDSR in The Cochrane Library provides a registry of systematic reviews, making complete and ongoing Cochrane reviews an essential reference resource when undertaking a new systematic review, as they provide an indication of content areas already covered so that effort is not duplicated. An initiative to develop an international registry for prospective registration of protocols for all systematic reviews is now underway [Booth et al., 2010] and will be invaluable in assisting those planning new reviews and updating existing ones.

\section{Acknowledgements}

This work was performed independent of any funding. S.I. is a PhD student supervised by V.C.C.M. and R.E.C. at Queen Mary, University of London.

\section{Disclosure Statement}

V.C.C.M. is an editor of the Cochrane Oral Health Group and the lead author in a series of Cochrane Topical fluoride reviews. S.I. and R.E.C. are review authors with the same group. None of the authors have any financial conflict of interests to declare. 


\section{References}

-Al Faleh K, Al-Omran M: Reporting and methodologic quality of Cochrane Neonatal review group systematic reviews. BMC Pediatr 2009;9:38.

-Alvarez F, Meyer N, Gourraud PA, Paul C: Consort adoption and quality of reporting of randomized controlled trials: a systematic analysis in two dermatology journals. Br J Dermatol 2009;161:1159-1165.

-Ammari A, Bloch-Zupan A, Ashley PF: Systematic review of studies comparing the anticaries efficacy of children's toothpaste containing $600 \mathrm{ppm}$ of fluoride or less with high fluoride toothpastes of $1,000 \mathrm{ppm}$ or above. Caries Res 2003;37:85-92.

-Ammari JB, Baqain ZH, Ashley PF, Ammari JB, Baqain ZH, Ashley PF: Effects of programs for prevention of early childhood caries. A systematic review. Med Princ Pract 2007;16: 437-442.

-Antman EM, Lau J, Kupelnick B, Mosteller F, Chalmers TC: A comparison of results of meta-analyses of randomized control trials and recommendations of clinical experts: treatments for myocardial infarction. JAMA 1992;268:240-248.

-Axelsson S, Söder B, Nordenram G, Petersson LG, Dahlgren H, Norlund A, Källestål C, Mejàre I, Lingström $\mathrm{P}$, Lagerlöf $\mathrm{F}$, Holm AK, Twetman S: Effect of combined caries-preventive methods: a systematic review of controlled clinical trials. Acta Odontol Scand 2004;62:163-169.

-Azarpazhooh A, Main PA, Azarpazhooh A, Main PA: Fluoride varnish in the prevention of dental caries in children and adolescents: a systematic review. J Can Dent Assoc 2008; 74:73-79.

Bader J, Ismail A: Survey of systematic reviews in dentistry. J Am Dent Assoc 2004; 135:464473.

Bader JD, Rozier RG, Lohr KN, Frame PS: Physicians' roles in preventing dental caries in preschool children: a summary of the evidence for the U.S. Preventive Services Task Force. Am J Prev Med 2004;26:315-325.

- Bader JD, Shugars DA, Bonito AJ: A systematic review of selected caries prevention and management methods. Community Dent Oral Epidemiol 2001;29:399-411.

- Bartizek RD, Gerlach RW, Faller RV, Jacobs SA, Bollmer BW, Biesbrock AR: Reduction in dental caries with four concentrations of sodium fluoride in a dentifrice: a meta-analysis evaluation. J Clin Dent 2001;12:57-62.

Beiswanger BB, Stookey GK: The comparative clinical cariostatic efficacy of sodium fluoride and sodium monofluorophosphate dentifrices: a review of trials. J Dent Child 1989; 56:337-347

Benson PE, Parkin N, Millett DT, Dyer F, Vine S, Shah A: Fluorides for the prevention of white spots on teeth during fixed brace treatment. Cochrane Database Syst Rev 2004; 3:CD003809.
Booth A, Clarke M, Ghersi D, Moher D, Petticrew M, Stewart L: An international registry of systematic-review protocols. Lancet 2010, E-pub ahead of print.

CRD: CRD Report 4. Undertaking systematic reviews of research on effectiveness: CRD guidelines for those carrying out or commissioning reviews. York, Centre for Reviews and Dissemination, University of York, 1996.

Chadwick BL, Roy J, Knox J, Treasure ET: The effect of topical fluorides on decalcification in patients with fixed orthodontic appliances: a systematic review. Am J Orthod Dentofacial Orthop 2005;128:601-606.

Chaves SC, Vieira-da-Silva LM: Anticaries effectiveness of fluoride toothpaste: a meta-analysis (in Portuguese). Rev Saude Publica 2002 36:598-606.

Clark DC, Hanley JA, Stamm JW, Weinstein PL: An empirically based system to estimate the effectiveness of caries-preventive agents: a comparison of the effectiveness estimates of APF gels and solutions, and fluoride varnishes. Caries Res 1985;19:83-95.

Clarke M, Oxman A: Cochrane reviewers handbook 4.1.5 (updated April 2002); in The Cochrane Library issue 2. Oxford, Update Software 2002.

Deeks JJ: Chapter 9: Analysing data and undertaking meta-analyses; in Higgins JPT, Green S (eds): Cochrane Handbook for Systematic Reviews of Interventions version 501 (updated September 2008). The Cochrane Collaboration, 2008.

Delaney A, Bagshaw S, Ferland A, Manns B, Laupland K, Doig C: A systematic evaluation of the quality of meta-analyses in the critical care literature. Crit Care 2005;9:R575-R582.

Derks A, Katsaros C, Frencken JE, van't Hof MA, Kuijpers-Jagtman AM: Caries-inhibiting effect of preventive measures during orthodontic treatment with fixed appliances: a systematic review. Caries Res 2004;38:413420.

Glenny A, Esposito M, Coulthard P, Worthington HV: The assessment of systematic reviews in dentistry. Eur J Oral Sci 2003;111: 85-92.

-Griffin SO, Regnier E, Griffin PM, Huntley V: Effectiveness of fluoride in preventing caries in adults. J Dent Res 2007;86:410-415.

- Heijnsbroek M, Paraskevas S, Van der Weijden GA: Fluoride interventions for root caries: a review. Oral Health Prev Dent 2007;5:145152.

Helfenstein U, Steiner M: Fluoride varnishes (Duraphat): a meta-analysis. Community Dent Oral Epidemiol 1994;22:1-5.

Higgins J, Altman D: Chapter 8: Assessing risk of bias in included studies; in Higgins JPT, Green S (eds): Cochrane Handbook for Systematic Reviews of Interventions version 501 (updated September 2008). The Cochrane Collaboration, 2008.
Higgins JPT, Green S (eds): Cochrane Handbook for Systematic Reviews of Interventions version 501 (updated September 2008). The Cochrane Collaboration, 2008.

Higgins J, Thompson S, Deeks J, Altman D: Statistical heterogeneity in systematic reviews of clinical trials: a critical appraisal of guidelines and practice. J Health Serv Res Policy 2002;7:51-61.

Hiiri A, Ahovuo-Saloranta A, Nordblad A, Mäkelä M: Pit and fissure sealants versus fluoride varnishes for preventing dental decay in children and adolescents. Cochrane Database Syst Rev 2006;4:CD003067.

Johnson MF: Comparative efficacy of $\mathrm{NaF}$ and SMFP dentifrices in caries prevention: a meta-analytic overview. Caries Res 1993;27: 328-336.

Jørgensen A, Hilden J, Gøtzsche PG: Cochrane reviews compared with industry supported meta-analysis and other meta-analysis of the same drugs: systematic review. BMJ 2006; 333:782-785

Jørgensen A, Maric K, Tendal B, Faurschou A, Gøtzsche P: Industry-supported meta-analyses compared with meta-analyses with nonprofit or no support: differences in methodological quality and conclusions. BMC Med Res Methodol 2008;8:60.

Källestål C, Norlund A, Söder B, Nordenram G, Dahlgren H, Petersson LG, Lagerlöf F, Axelsson S, Lingström P, Mejàre I, Holm AK, Twetman S: Economic evaluation of dental caries prevention: a systematic review. Acta Odontol Scand 2003;61:341-346.

Kay EJ, Locker D: Is dental health education effective? A systematic review of current evidence. Community Dent Oral Epidemiol 1996;24:231-235.

Liberati A, Altman DG, Tetzlaff J, Mulrow C, Gøtzsche PC, Ioannidis JPA, Clarke M, Devereaux PJ, Kleijnen J, Moher D: The PRISMA statement for reporting systematic reviews and meta-analyses of studies that evaluate healthcare interventions: explanation and elaboration. BMJ 2009;339:b2700.

$>$ Lundh A, Knijnenburg SL, Jørgensen AW, van Dalen EC, Kremer LC: Quality of systematic reviews in pediatric oncology: a systematic review. Cancer Treat Rev 2009;35:645-652.

-Major MP, Major PW, Flores-Mir C: An evaluation of search and selection methods used in dental systematic reviews published in English. J Am Dent Assoc 2006;137:1252-1257.

Marinho VC: Systematic reviews of controlled trials in general and oral health care. Braz J Oral Sci 2003;2:215-226.

Marinho VC, Higgins JP, Logan S, Sheiham A: Fluoride varnishes for preventing dental caries in children and adolescents. Cochrane Database Syst Rev 2002a;3:CD002279. 
Marinho VC, Higgins JP, Logan S, Sheiham A: Topical fluoride (toothpastes, mouthrinses, gels or varnishes) for preventing dental caries in children and adolescents. Cochrane Database Syst Rev 2003a;4:CD002782.

Marinho VC, Higgins JP, Logan S, Sheiham A: Fluoride mouthrinses for preventing dental caries in children and adolescents. Cochrane Database Syst Rev 2003c;3:CD002284.

Marinho VC, Higgins JP, Logan S, Sheiham A: Combinations of topical fluoride (toothpastes, mouthrinses, gels, varnishes) versus single topical fluoride for preventing dental caries in children and adolescents. Cochrane Database Syst Rev 2004a;1:CD002781.

Marinho VC, Higgins JP, Logan S, Sheiham A: One topical fluoride (toothpastes, or mouthrinses, or gels, or varnishes) versus another for preventing dental caries in children and adolescents. Cochrane Database Syst Rev 2004b;1:CD002780.

Marinho VC, Higgins JP, Logan S, Sheiham A: Fluoride gels for preventing dental caries in children and adolescents. Cochrane Database Syst Rev 2002b;2:CD002280.

Marinho VC, Higgins JP, Sheiham A, Logan S: Fluoride toothpastes for preventing dental caries in children and adolescents. Cochrane Database Syst Rev 2003b;1:CD002278.

- Moher D, Cook DJ, Eastwood S, Olkin I, Rennie D, Stroup DF: Improving the quality of reports of meta-analyses of randomised controlled trials: the QUOROM statement. Lancet 1999;354:1896-1900.

- Moher D, Jones A, Lepage L, for the CONSORT Group: Use of the consort statement and quality of reports of randomized trials: a comparative before-and-after evaluation. JAMA 2001;285:1992-1995.

- Moher D, Liberati A, Tetzlaff J, Altman DG, for the PG: Preferred reporting items for systematic reviews and meta-analyses: The PRISMA statement. BMJ 2009;339:b2535.

- Moher D, Tetzlaff J, Tricco AC, Sampson M, Altman DG: Epidemiology and reporting characteristics of systematic reviews. PLoS Med 2007;4:e78.

- Moja LP, Telaro E, D’Amico R, Moschetti I, Coe L, Liberati A, on behalf of the Metaquality Study G: Assessment of methodological quality of primary studies by systematic reviews: results of the metaquality cross sectional study. BMJ 2005;330:1053.
Mrkobrada M, Thiessen-Philbrook H, Haynes RB, Iansavichus AV, Rehman F, Garg AX: Need for quality improvement in renal systematic reviews. Clin J Am Soc Nephrol 2008;3:1102-1114.

Oxman A, Guyatt G: Validation of an index of the quality of review articles. J Clin Epidemiol 1991;44:1271-1278.

-Oxman A, Guyatt G: The science of reviewing research. Ann N Y Acad Sci 1993;703:125133.

Petersson LG, Twetman S, Dahlgren H, Norlund A, Holm AK, Nordenram G, Lagerlöf F, Söder B, Källestål C, Mejàre I, Axelsson S, Lingström P: Professional fluoride varnish treatment for caries control: a systematic review of clinical trials. Acta Odontol Scand 2004;62:170-176.

Plint AC, Moher D, Morrison A, Schulz K, Altman DG, Hill C, Gaboury I: Does the consort checklist improve the quality of reports of randomised controlled trials? A systematic review. Med J Aust 2006;185:263-267.

Richards D: 10 years after. Evid Based Dent 2004; 5:87.

Rosenblatt A, Stamford TC, Niederman R: Silver diamine fluoride: a caries 'silver-fluoride bullet'. J Dent Res 2009;88:116-125.

- Rozier RG: Effectiveness of methods used by dental professionals for the primary prevention of dental caries. J Dent Educ 2001;65: 1063-1072.

-Shea B, Grimshaw J, Wells G, Boers M, Andersson N, Hamel C, Porter A, Tugwell P, Moher D, Bouter L: Development of AMSTAR: a measurement tool to assess the methodological quality of systematic reviews. BMC Med Res Methodol 2007;7:10.

-Shea BJ, Hamel C, Wells GA, Bouter LM, Kristjansson E, Grimshaw J, Henry DA, Boers M: AMSTAR is a reliable and valid measurement tool to assess the methodological quality of systematic reviews. J Clin Epidemiol 2009;62:1013-1020.

-Sørensen HT, Rothman KJ: The prognosis for research. BMJ 2010;340:c703.

-Stamm JW, Bohannan HM, Graves RC, Disney JA: The efficiency of caries prevention with weekly fluoride mouthrinses. J Dent Educ 1984;48:617-626.

-Steiner M, Helfenstein U, Menghini G: Effect of $1000 \mathrm{ppm}$ relative to $250 \mathrm{ppm}$ fluoride toothpaste: a meta-analysis. Am J Dent 2004;17: $85-88$.
Sterne JAC, Egger M, Moher D: Chapter 10: Addressing reporting biases; in Higgins JPT, Green S (eds): Cochrane Handbook for Systematic Reviews of Interventions, version 501 (updated September 2008). The Cochrane Collaboration, 2008.

-Stookey GK, DePaola PF, Featherstone JD, Fejerskov O, Möller IJ, Rotberg S, Stephen KW, Wefel JS: A critical review of the relative anticaries efficacy of sodium fluoride and sodium monofluorophosphate dentifrices. Caries Res 1993;27:337-360.

Strohmenger L, Brambilla E: The use of fluoride varnishes in the prevention of dental caries: a short review. Oral Dis 2001;7:71-80.

- Twetman S: Prevention of early childhood caries (ECC): review of literature published 19982007. Eur Arch Paediatr Dent 2008;9:12-18.

Twetman S, Axelsson S, Dahlgren H, Holm AK, Källestål C, Lagerlöf F, Lingström P, Mejàre I, Nordenram G, Norlund A, Petersson LG, Söder B: Caries-preventive effect of fluoride toothpaste: a systematic review. Acta Odontol Scand 2003;61:347-355.

- Twetman S, Petersson L, Axelsson S, Dahlgren H, Holm AK, Källestål C, Lagerlöf F, Lingström P, Mejàre I, Nordenram G, Norlund A, Söder B: Caries-preventive effect of sodium fluoride mouthrinses: a systematic review of controlled clinical trials. Acta Odontol Scand 2004;62:223-230.

-Van Rijkom HM, Truin GJ, van't Hof MA: A meta-analysis of clinical studies on the caries-inhibiting effect of fluoride gel treatment. Caries Res 1998;32:83-92.

-Volpe A, Petrone M, Davies R, Proskin H: Clinical anticaries efficacy of NaF and SMFP dentifrices: overview and resolution of the scientific controversy. J Clin Dent 1995;6(spec No):1-28.

Walsh T, Worthington H, Glenny A, Appelbe P, Marinho V, Shi X: Fluoride toothpastes of different concentrations for preventing dental caries in children and adolescents. Cochrane Database Syst Rev 2010;1:CD007868.

Wong MCM, Glenny AM, Tsang BWK, Lo ECM, Worthington HV, Marinho VCC: Topical fluoride as a cause of dental fluorosis in children. Cochrane Database Syst Rev 2010;1: CD007693. 